\title{
Assessment and Evaluation Techniques
}

\author{
Tatiana Baranovskaya \\ Higher School of Economics Research University
}

\begin{abstract}
Correspondence concerning this article should be addressed to Tatiana Baranovskaya, National Research University Higher School of Economics, Malaya Pionerskaya, 12, Moscow, Russian Federation, 115054. E-mail: tbaranovskaya@hse.ru
\end{abstract}

Valentina Shaforostova

Higher School of Economics Research University

\begin{abstract}
Correspondence concerning this article should be addressed to Valentina Shaforostova, National Research University Higher School of Economics, Malaya Pionerskaya, 12, Moscow, Russian Federation, 115054. E-mail: shafo@hse.ru
\end{abstract}

\begin{abstract}
Assessment and evaluation have always been important; they are linked to language teaching methodology, program outcomes, language teacher competencies, language standards and second language acquisition training. They can serve many different policies and can come in different forms. Assessment and evaluation have always been seen as the responsibility of the specialists, but they have rarely been included as a component in English language teacher (ELT) training. However, the ELT field has been experiencing a major shift in assessment and evaluation with effects on teachers, and learners around the world. It has also been influenced by a major questioning of traditional forms of testing and the underlying psychometric principles of measurement in ELT. Recent studies reveal that the reconceptualization of English language assessment and evaluation provides systematic information about student learning in relation to their performance and contributes to better understanding of their strengths and weaknesses. In many ways ELT has lagged behind the rest of education in the exploration of new theories and assessment and evaluation tools, including self-assessment. This research gap was generated partly because of the lack of integration with mainstream educational theory and practice in many areas of ELT, and partly because of powerful positions of traditional English language tests. The attempt to bridge this gap has lead to the research carried out. The aim of this article is to elaborate different assessment techniques that may better address student learning needs, improve student learning and engage students in self-assessment, including the sequence of steps that could lead to self-assessment. The study shows that the techniques implemented to develop self-assessment enable students to perform well.
\end{abstract}

Keywords: evaluation, assessment, important, English language

This article examines the importance of assessment and evaluation A major concern of English language teaching has been assessing and evaluating students' progress during the course of study as well as their achievements at the end of it. The methodology of this paper is a qualitative approach using classroom activities and library sources as well as other related research in an attempt to improve students' knowledge and learning. Assessment and evaluation also give teachers useful information on how to improve their teaching methods.

Assessment and evaluation are very important parts of the constructive alignment process. Welldesigned assessments can allow students to use the knowledge and skills they have learnt and indicate their level of mastery. The feedback on the assessment will also provide students with clear information on the criteria they need to succeed at assigned tasks, 
can give the lecturer a clearer sense of how the task is assessing mastery and what aspects are being assessed. Evaluation of the course or module, by students and lecturers should feed back into the whole process of curriculum alignment, as well as reflect critically and constructively on the outcomes, the teaching and learning activities, the assessment and the experience of the course or module. Reflexivity, continuous learning and development are key aims of successful evaluation.

Through the use of appropriate classroom assessment strategies and techniques, teachers can increase their students' motivation and show them how well they have learned the language. Evaluation goes beyond learners' achievements and language assessment to consider all aspects of teaching and learning. Although the terms 'assessment' and 'evaluation' are often used interchangeably, they can be considered two parts of the same process. Assessment is the process of gathering evidence of what the child can do. Evaluation is the process that follows this collection of data, including analysis and reflection, as well as decisions based on the data.

This paper will present some useful assessment and evaluation techniques that can assist language teachers to create a dynamic classroom situation for evaluation. It will show that the quality of the assessment and evaluation in the educational process has a profound link to students' performance and can engage them in self-assessment which is most important in English language teaching.

\section{Materials and Methods}

\section{Theoretical Background}

The present study focuses upon the qualitative approach of English language learning assessment and evaluation process in the educational system. Evaluation in teaching the English language is a process of collecting, analysing and interpreting information about teaching and learning in order to make informed decisions that enhance student achievement and the success of educational programs (Rea-Dickens \& Germanie, 1993; Genesee \& Upshur, 1996; O’Mally \& Valdez-Pierce, 1996). Evaluation is a process that includes five basic components:

- Articulating the purpose of the educational system;

- Identifying and collecting relevant information;

- Having ideas that are valuable and useful to learners in their lives and professions;

- Analysing and interpreting information for learners;

- Classroom management or classroom decision making.

In classroom assessment, since teachers themselves develop, administer and analyse the questions, they are more likely to apply the results of the assessment to their own teaching. Therefore, it provides feedback on the effectiveness of instruction and gives students a measure of their progress. As Biggs (1999) maintains, two major functions can be pointed out for classroom assessment: one is to show whether or not learning has been successful, and the other one is to clarify the expectations teachers have of the students (Dunn et al., 2004).

Assessment plays a number of roles in the life of a student, some of which they may be more aware of than others. It is widely accepted that students' learning patterns, educational focus, and allocation of time will be directly influenced by assessment. It does more than allocate a grade or degree classification to students - assessment plays an important role in focusing their attention and, as Sainsbury \& Walker (2007) observe, actually drives their learning. Gibbs (2003) states that assessment has 6 main functions:

1. Capturing student time and attention;

2. Generating appropriate student learning activity;

3. Providing timely feedback which students pay attention to;

4. Helping students to internalise the discipline's standards and notions of equality;

5. Generating marks or grades which distinguish among students or enable pass/fail decisions to be made;

6. Providing evidence enables them to judge the appropriateness of course standards.

He states that, with the exception of the last two points, these functions should occur as frequently as possible to support effective learning.

The purpose of classroom assessment and evaluation is to give students the opportunity to show what they have learned rather than catching them out or to show what they have not learned. Needless to say, evaluation and assessment can focus on different aspects of teaching and learning: respectively, textbooks and instructional materials, student achievement, and whole programs of instruction.

It is important to clarify the distinction between evaluation and assessment. These terms are often used interchangeably and are, in fact, related, but they are technically different. Assessment of an individual student's progress or achievement is an important component of evaluation: it is that part of evaluation that includes the measurement and analysis of information about student learning. The primary focus of assessment in English Language Teaching has been language assessment and the role of tests in assessing students' language skills. Evaluation goes beyond 
student achievement and language assessment to consider all aspects of teaching and learning and to look at how educational decisions can be made on the basis of alternative forms of assessment. Gensee (cited in Carter \& Nunan, 2001) believes that another purpose of evaluation is to guide classroom instruction and enhance student learning on a day-to-day basis. Classroom assessment and evaluation concerns:

- Suitability of general instructional goals and objectives associated with an individual lesson or unit plans;

- Effectiveness of instructional methods, materials and activities used to attain instructional objectives;

- Adequacy of professional resources required to deliver instruction.

Classroom assessment and evaluation under the active management of teachers can also serve important professional development purposes since the information resulting from such evaluations provides teachers with valuable feedback about their instructional effectiveness that they can use to develop and improve their professional skills. As part of reflective teaching movement, teachers are encouraged to conduct research in their own classrooms (Nunan, 1989b; Allwright \& Baily, 1991; Richards \& Lockhart, 1994); classroom assessment and evaluation is an important part of such research.

Assessment is perhaps one of the most important elements of curriculum design and alignment, because this is where it is possible to see if students can demonstrate mastery in terms of the knowledge and skills they need to have learnt. Assessment, in a constructively aligned curriculum, must speak to the outcomes listed for the course. It must draw in both the knowledge and the practical and intellectual skills and competencies that students have been taught and that they have practiced in lectures and tutorials. Assessment activities must test what has been learnt and taught, and should not be constructed so as to be ambiguous or inexplicit.

Assessment tasks can be formative and summative. The former give students opportunities to make errors and get constructive, guiding feedback used to develop competency and understanding in further assessments and teaching and learning. Formative quizzes, essays that can be drafted and revised, and short written or verbal tasks that receive detailed feedback are examples of formative assessments. They are opportunities for the students to demonstrate mastery or competence in a particular area or across several areas that have been studied. The feedback is usually less detailed and aimed more at providing a summary of what they have and have not yet mastered. Examinations, some kinds of tests and theses or dissertations are examples of summative assessments.

Feedback is a very important part of the assessment process, both formative and summative. Through receiving focused, relevant and guiding feedback, students are able to understand where their strengths and weaknesses are, and where they still need to concentrate their efforts in terms of their own learning. Through giving feedback, lecturers and tutors are better able to make similar assessments of strengths and weaknesses for students. This can enable more responsive teaching and tutoring to address gaps and weaknesses where necessary. It can also provide a better understanding of how students are responding to the methods and styles of teaching and tutoring. It can further show how deeply and accurately the students grasp and understand the relevant knowledge and employ the related skills and practices to explore and demonstrate their knowledge.

Evaluation is an important part of an aligned curriculum and an overall teaching and learning strategy because it is a part of the feedback and development cycle. It should be a part of any responsive and up-to-date teaching and learning strategy or plan. Evaluation gives students opportunities to speak to the lecturer about their experiences and impressions of the course content and the pedagogical approaches that have been used. It, therefore, gives lecturers valuable insights into how they teach and how effectively instruction has been taken up by the students.

One of the most important issues in evaluation is timing. Teachers can use quick exercises to check in with students during the course, at the end of a topic or after an assignment has been completed. Longer and more detailed evaluation for the end of a course can also be created. Students who did the course last year can be asked to complete a retrospective evaluation. The important thing to consider when thinking about the timing is the purpose of the evaluation (what do students need to know and why), and what teachers plan to do with the information students give them.

Gensee and Upshur (1996) state that classroom assessment and evaluation is concerned primarily with improving instruction in order to help enhance students' learning. Teachers in any educational system are actively and continuously involved in assessment and evaluation. Students can also be active participants in assessing their own achievements and in planning how they will study and learn a second language, i.e. they can be engaged in the early stages of the process of self-assessment. The context of classroom assessment and evaluation is summarized by Gensee and Upshur (1996) in the following figure: 


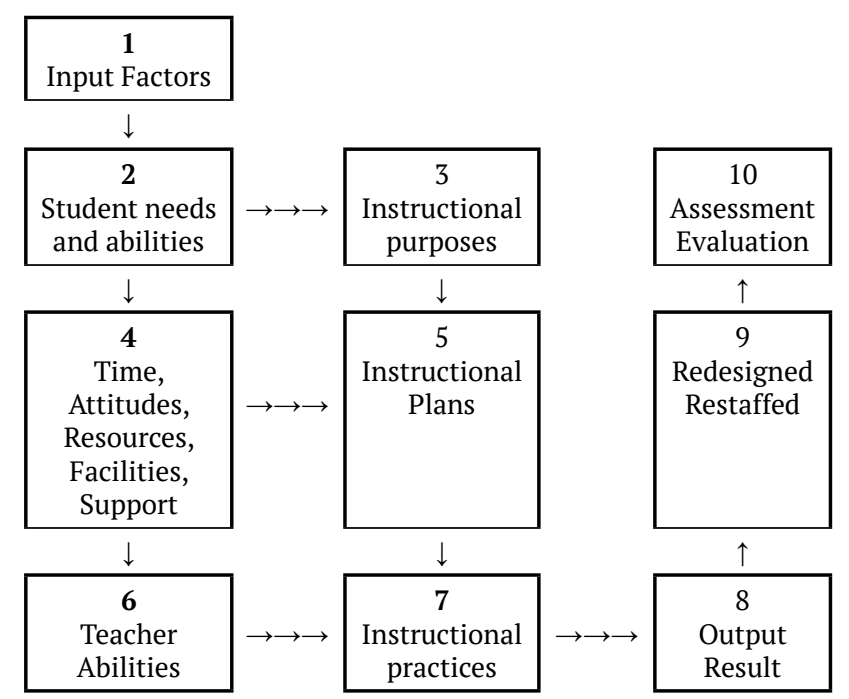

Figure 1. The context of classroom assessment and evaluation.

Any instruction consists of three components: first, the purposes identify the objectives of instruction the "WHY"; second, the plans describe the means of attaining those objectives - the "HOW"; third, practice reveals what actually takes place in the classroom - the "WHAT". Gensee and Upshur (1996) also discuss other factors, which are not part of classroom instruction itself, but can have a significant effect on second language teaching and learning. They refer to these additional factors as "input factors." Thus, it can be said that classroom assessment and instruction have four aspects, namely: purposes, plans, practices, and input factors.

Instructional objectives are identified as the goals that a teacher sets while teaching. On the one hand, they provide direction for planning appropriate instruction and, on the other hand, they provide a basis for determining whether a student has achieved what a teacher has set out to accomplish. They provide criteria for assessing the outcomes of students' learning and monitoring their performance. Different kinds of objectives can guide classroom instruction: 1) language, 2) strategic, 3) socio-affective, 4) philosophical, and 5) method or process.

Language objectives refer to language skills that learners are expected to acquire in the classroom. Objectives that are concerned with strategies for communicating, learning, and critical thinking are referred to as "strategic objectives". Learning process refers to a "conscious processes and techniques that facilitate the comprehension, acquisition, and retention of new skills and concepts" (Chamot \& O'Malley, 1989). According to Chamot and O'Malley, they may include metacognitive strategies (such as selective attention), cognitive strategies (such as summarizing and elaboration), or socio-affective strategies (such as questioning for clarification).

Socio-affective objectives refer to changes in learners' attitudes or social behaviour that result from classroom instruction (e.g. changes in attitudes toward the target language, the target language group, or the learner's first language group). However, in most cases these objectives are secondary to language learning objectives. Gensee (1996) deals with philosophical objectives as changes in attitudes, values, or beliefs of a more general nature than those associated with socioaffective objectives. And, finally, method or process objectives refer to methods, processes, experiences, materials, activities, or other aspects of instruction. Nevertheless, Gensee and Upshur (1996) state that the influence of these objectives is not equally useful for classroom instruction. They believe philosophical objectives, for example, are minimally useful. Strategic objectives help in understanding students' performances in class, thus, play an important role in instructional planning. They are, however, secondary to language acquisition; in other words, the effective deployment of certain strategies should lead to enhanced second language attainment and usage. Clearly, language objectives are fundamental to second language evaluation.

Gensee and Upshur (1996) argue that evaluation and assessment involve comparison. More specifically, decisions that result from assessment are arrived at by making comparisons. They claim that in order to evaluate and assess, it is necessary to understand the factors that influence student performance in class. This means going beyond the assessment of just achievement. Chastain (1988) believes that teachers need to constantly evaluate their teaching on the basis of student reaction, interest, motivation, preparation, participation, perseverance, and achievement. The conclusions drawn from such ongoing evaluation constitute their main source for measuring the effectiveness of selected learning activities.

Evaluation of achievement is the feedback that makes improvement possible. By means of evaluation, strengths and weaknesses are identified. Evaluation, in this sense, is another aspect of learning. It enables learners to grasp what they missed previously and helps the teacher to comprehend what can be done in subsequent lessons to improve learning. To do so, alternative methods (e.g. dialogue journals, portfolio conferences, interviews and questionnaires, observation, etc.) are available for collecting useful information about language learning and about student-related factors that influence the processes of language teaching and learning. It is widely accepted that the assessment/evaluation process involves the use of multiple sources of information collected in a variety of contexts. At the primary level, many teachers use observation, work samples, and questionnaires as tools in the process of assessment and evaluation.

\section{Methodology}


This article includes analyses of the evaluation and assessment tools carried out by teachers at the National Research University Higher School of Economics with fourth-year students in the Department of Public Administration. The main idea of the experiment was to develop students' ability to assess their own speaking skills. The expected skills of fourth-year students included: specialized knowledge and experience in conveying ideas and information clearly and in a well-organized manner; ability to give presentations; effective communication skills. To acquire these necessary skills in order to confidently and effectively interact in speaking situations, students should learn how to plan, organise and present information on a variety of topics. They should be able to give formal presentations at conferences as well as talk to experts, consultants, visiting researchers, etc.

Focusing on this primary task, the authors conducted an experiment on developing, improving, mastering and assessing oral presentation skills among the fourth-year students. At the end of the course the students were supposed to give presentations to accompany the formal written paper, i.e. a project proposal. The 90 students who took part in the experiment were split into six smaller groups: three of these groups were organised as Group 1; the other three groups comprised Group 2. Both groups were given instruction on oral presentation skills. But while the first group were given specific instruction about how they would be assessed and were shown the evaluation criteria for oral presentations, the second group received no explicit information regarding evaluation; the input they received was based solely on the fourth-year teaching materials (Kuzmenkova, 2011).

To assess students' level of English language competence at the beginning of the course, both groups were given Objective Placement Test, Variant 1 CUP \& FLTRP, 2010 (consisting of 60 multiple-choice questions divided into three sections Language Use (40 items), Reading (10 items), Listening (10 items)).

The results achieved of the first group of 43 students are presented in Table 1.

The second group of 47 students (whose results were rather close to the first group) results are presented in Table 2.

The pre-test showed that the level of the English language competence was practically equal in both groups.

To accomplish the objective of the study, the authors attempted to verify the role of continuous evaluation of different stages on their ability to master the special skills associated with giving presentations. With this task in mind, the authors conducted research with the first group of 43 students. The essence of the study was to evaluate each part of the presentation, which was to be introduced during the academic course.
Table 1

Assessment results of the first group (43 students)

\begin{tabular}{cc}
\hline $\begin{array}{c}\text { Number of } \\
\text { students }\end{array}$ & $\begin{array}{c}\text { Score } \\
\mathbf{( 6 0 )}\end{array}$ \\
\hline 4 & $55-58$ \\
\hline 5 & 53 \\
\hline 4 & 50 \\
\hline 9 & $45-49$ \\
\hline 9 & $41-44$ \\
\hline 5 & $37-40$ \\
\hline 3 & $32-35$ \\
\hline 2 & $28-30$ \\
\hline 2 & 27 \\
\hline
\end{tabular}

Table 2

Assessment results of the second group (47 students)

\begin{tabular}{cc}
\hline $\begin{array}{c}\text { Number of } \\
\text { students }\end{array}$ & $\begin{array}{c}\text { Score } \\
\mathbf{( 6 0 )}\end{array}$ \\
\hline 5 & $55-57$ \\
\hline 6 & $52-54$ \\
\hline 5 & 51 \\
\hline 10 & $47-49$ \\
\hline 8 & $41-45$ \\
\hline 4 & $38-40$ \\
\hline 3 & $34-36$ \\
\hline 4 & $29-32$ \\
\hline 2 & $26-27$ \\
\hline
\end{tabular}

\section{Results}

\section{Introducing a Presentation}

In Group 1, information shared on how to introduce a presentation and make it effective was provided by the teacher's input and the students were asked to select a problem that they felt deserved the special attention of the class. After that, they worked individually to prepare a one- to two-minute introduction for a presentation on the topic. When the task was completed, the students worked in small groups and they then took turns presenting their introductions to the group. Once all the introductions were presented, the strengths and weaknesses of each were discussed. Before the discussion, the instructor assigned different students to fill out the evaluation form and consider the following questions in analysing both positive and negative sides of each introduction.

1. How did the speaker attract listeners' interest and focus their attention on the topic?

2. What was the central idea of the presentation? Was it clearly stated?

3. What preview did the speaker give of the 
presentation organisation?

4. How did the speaker plan to handle questions from the audience?

5. Can you offer any suggestions for improving the introduction?

After that the listeners carefully studied the assessment criteria and justified the grade allocated.

Eventually the students were given a list of suggested topics (in alphabetical order) and optional guidelines:

A. Discuss a recent development or innovation in your field

Guidelines:

- How was it developed?

- What are its current and future applications or uses?

- What needs does the particular development meet?

- What, if any, are the problems associated with it?

B. Discuss a research project that you have carried out:

Guidelines:

- the purpose of the research;

- what you did;

- when and where you conducted the research;

- significant results/conclusions/ recommendations;

C. Imagine that you are speaking to some students who are interested in majoring in your particular field of study. Conduct a discussion on different job opportunities in this field.

\section{Determining Content}

Inevitably, at some point in preparing for a presentation, students began to be concerned about determining the content, that is, what specific information to include. Students were introduced to the structure and teachers emphasised that the focus of any informative presentation should be to communicate useful information in an explicit way. For the fourthyear students, the topic chosen for presentation was related to their studies or research projects. Once the subject issue was chosen, the topic would be limited in order to cover the information adequately within the time available for the presentation. When students selected the topic for their presentations they also considered the following points:

1. Do you have enough time and resources to conduct the necessary research?

2. Have you narrowed the topic enough to cover it adequately within the time limits?

3. Is the topic of potential interest to your listeners?

4. Is the topic too easy/too difficult or too technical for the audience?
5. What do your peers want or need to know about this subject?

After that, the teacher wanted the students to write down two topics from their field of the research that they thought would be suitable for a five- to ten-minute presentation to be given to students in the class. The instructor collected these topics, listed them on the board and asked students to work in small groups. The students in groups analysed each topic, considered whether it was too limited, too general, too technical or too well-known for the audience. Moreover, if the students found the topic unsatisfactory, they revised it to make it adequate for delivering a precise message.

\section{Concluding a Presentation}

To make a strong impression on listeners, the conclusion of the presentation should be brief and to the point of the talk. For example, when presenting conclusions, students are instructed that it is not the time and place to introduce new ideas, but to remind the audience of what has already been presented by reviewing the main points and emphasising the major issues. The listeners are prepared for the end of the talk through some signalling strategies for concluding a presentation; for example, "And now let me quickly review the main points (advantages, reasons, effects, types) of ."

Having identified the main features of conclusion, the teacher assigned the tasks for writing conclusions using the sametopics that weregiven as the examples for writing an introduction. Students worked individually to prepare a one- or two-minute conclusion to a presentation they selected. When everyone finished, they started to work in small groups, taking turns presenting conclusions to the group. Within the small groups, strengths and weaknesses were discussed and then results were reported to the whole group.

After studying the information on determining the content and preparing the conclusion of the presentation, students prepared a four- or five-minute talk to give to a group or to the entire class, taking into account the following guidelines:

- making an outline of the points to be presented (avoiding writing out every word of the presentation)

- making sure the points were put in a logical order

- planning the introduction and conclusion

- making up a short list of any specialised or technical terms, etc.

The teacher assigned some students the task of evaluating the presentations. These listeners considered the following questions in analysing strengths and weaknesses of the content presented:

1. What kind of details, examples or facts related to the topic did the speaker include? 
2. Did the speaker use the appropriate vocabulary?

3. Was it the right level for these particular listeners in terms of understanding?

4. Was the information too simple or too complex for the audience?

5. Did the presentation meet the time requirements?

They also examined the positive and negative sides of the conclusion focusing on the following questions:

1. Did the speaker use a fixed phrase to lead into the conclusion? What was it?

2. Was there a summary of the main points of the presentation?

3. Did the presenter highlight the major issues?

4. How did the speaker elicit questions from the audience?

5. If the conclusion did not meet the format how could it be improved?

According to the teacher's instructions, the listeners then reported the results to the speakers and the rest of the class, and finally discussed them.

In terms of organising information, determining the central idea explains exactly what aspect of the topic is to be covered. Thus, the central idea controls what is included in the presentation and also determines the arrangement of the main points.

\section{Organising Information}

For example, the chosen subject 'International Cooperation', could be developed in a variety of ways: a) the history of creation; b) the importance of international cooperation to avoid dangers, solve problems; c) working together with the UN and other organisations to deal with international problems; d) priorities of international cooperation: a. the environment $b$. economic cooperation c. regional infrastructure $d$. the indigenous population e. social aspects f. cross-border cooperation, etc.

To build up several different topics with a clear central idea, the teacher asked the students to work in small groups. Each group was given the list of general subjects:

- Public Administration

- Civil Service

- Procurement

- Bureaucracy

- Corruption

- Budgeting

- E-Government

- Knowledge Management

- Public-Service Motivation

- Crowdfunding

Working in a group, the students compared their topics, reported their results and finally selected those that sounded most relevant to the subject. The teacher emphasised that the central idea is the main body of the presentation. It consists of key points that need to be arranged for the audience in an easy way to understand and remember. Some of the most commonly used patterns of organisation are: (a) topical, (b) chronological, (c) spatial, (d) problem-solution, (e) cause and effect, (f) comparison/contrast (Matthews \& Marino, 1990). For example, in comparison/contrast pattern, there are two basic ways to follow when two things are compared or contrasted: A-B and point-bypoint. In the first type, the two things to be compared are discussed in turn to give a general picture of the comparison by focusing first on A then on B. While in the second type, the point-by-point approach, specific details are emphasised, alternating between A and B. The plan for this pattern is given in a Table 3.

Table 3

Two solutions to a problem

\begin{tabular}{|c|c|c|c|}
\hline \multicolumn{4}{|c|}{ To compare two solutions to a problem } \\
\hline \multicolumn{2}{|c|}{ A-B type } & \multicolumn{2}{|c|}{ Point-by-point type } \\
\hline \multicolumn{2}{|c|}{ I. Solution 1} & \multicolumn{2}{|c|}{ I. Cost } \\
\hline A. & Cost & A. & Solution 1 \\
\hline B. & Practicality & B. & Solution 2 \\
\hline C. & Side effects & \multicolumn{2}{|c|}{ II. Practicality } \\
\hline D. & Disadvantages & A. & Solution 1 \\
\hline E. & Advantages & B. & Solution 2 \\
\hline \multicolumn{2}{|c|}{ II. Solution 2} & \multicolumn{2}{|c|}{ III. Side effects } \\
\hline \multicolumn{2}{|c|}{ A. Cost } & A. & Solution 1 \\
\hline \multicolumn{2}{|c|}{ B. Practicality } & B. & Solution 2 \\
\hline \multicolumn{2}{|c|}{ C. Side effects } & \multicolumn{2}{|c|}{ IY. Disadvantages } \\
\hline \multicolumn{2}{|c|}{ D. Disadvantages } & \multicolumn{2}{|r|}{ Solution 1} \\
\hline \multirow{4}{*}{\multicolumn{2}{|c|}{ E. Advantages }} & B. & Solution 1 \\
\hline & & \multicolumn{2}{|c|}{ Y. Advantages } \\
\hline & & A. & Solution 1 \\
\hline & & B. & Solution 1 \\
\hline
\end{tabular}

Further, the teacher asked the students to work in small groups to determine which pattern of organisation would work best with the general subjects suggested earlier. When the students finished the task, they discussed the results in their groups. After giving some time for comparing the patterns, the teacher invited one person from each group to present the outline of their topics on the board. The audience made comments, pointed to positive and negative sides and improved the imperfect ones.

\section{Using Transitions}

In order for the listeners to understand the relationship of the ideas and to show them how the pieces of information fit together into a logical pattern, transitions need to be used. The students were given the task to work individually, planning their presentations with the focus on outlining and using 
transitions effectively, moving from point to point and connecting different parts of the talk.

When individual work came to an end, the teacher instructed the students to work in groups, taking turns giving their presentations. After each speaker had finished, the discussion of strengths and weaknesses was initiated. Having practiced in groups, some of the students were asked by the teacher to give presentations to the entire class. Meanwhile the teacher also assigned some students to do the following listening task:

1. What was the central idea of the presentation?

2. What pattern of organisation did the speaker use?

3. What were the main points presented by the speaker?

4. Were the main points presented in a logical way?

5. How well-connected were the different parts and ideas of the presentation?

Turning to the conditions of the experiment the first group under research was aware of the examination speaking criteria while the students of the second group were not presented the criteria and were not evaluated according to these criteria as the first group was.

To see the effect of the experiment and to assess students' level of English language competences in terms of general English, the students were given Objective Placement Test, Variant 2, CUP \& FLTRP, 2010 before the exam of the fourth-year academic course. This post-test revealed a definite progress in the first group:

Table 4

Post-test scores of the first group

\begin{tabular}{cc}
\hline $\begin{array}{c}\text { Number of } \\
\text { students (43) }\end{array}$ & $\begin{array}{c}\text { Score } \\
\mathbf{( 6 0 )}\end{array}$ \\
\hline 7 & 60 \\
\hline 6 & $57-58$ \\
\hline 5 & $53-55$ \\
\hline 7 & $48-50$ \\
\hline 7 & $45-47$ \\
\hline 5 & $41-43$ \\
\hline 3 & $38-40$ \\
\hline 3 & $33-36$ \\
\hline
\end{tabular}

While the results of the second group did not improve much (see Table 5).

Therefore, the authors were persuaded that continuous evaluation and awareness of the assessment criteria had a positive impact on the process of students' further development in the field of English language training. Moreover, these methods led to remarkable results at the final examination.
Table 5

Post-test scores of the second group

\begin{tabular}{cc}
\hline $\begin{array}{c}\text { Number of } \\
\text { students (47) }\end{array}$ & $\begin{array}{c}\text { Score } \\
\mathbf{( 6 0 )}\end{array}$ \\
\hline 5 & $56-58$ \\
\hline 6 & $53-55$ \\
\hline 5 & $49-50$ \\
\hline 8 & $48-49$ \\
\hline 8 & $42-46$ \\
\hline 6 & $39-41$ \\
\hline 4 & $35-37$ \\
\hline 5 & $30-33$ \\
\hline
\end{tabular}

\section{Discussion}

The present study provides an overview of assessment techniques pertinent to English language training in the field of oral speech. This exploration can help to understand the extent to which these learningoriented techniques of assessment affect competence in English language learning and lead to self-assessment, which plays an active role in English Learning Teaching. This issue has not been studied so far and the main aim of the present study was to observe and characterise these effects. The research consistently showed that only assessment "for learning" and not "of learning" lead to self-assessment. A sequence of steps to develop self-assessment was worked out: setting goals for students; the assessment of each language component; guidance of the teacher in discussions; clear references if students needed further review; teacher insights into student motivation. These patterns were repeated several times. They proved to demonstrate permanent progress. The development of the assessment techniques encourages the active involvement of students in the process of their own learning and assessment. These results indicate that the techniques implemented to develop assessment and self-assessment are intended to shift the focus more to students, enabling them to become more effective learners and to succeed in English language learning.

\section{Conclusion}

The research conducted by the authors shows that the framework used in assessment produces good results. It outlines the relationship between assessment and self-assessment. The authors argued that selfassessment plays a major role in ELT and explored 
the assessment activities which they embedded in the curriculum to develop self-assessment. The research shows that the impact on learning outcomes was great. The degree of English learning competence improvement helped students to develop and perfect their language skills.

The research into assessment and evaluation in ELT highlights several broad themes for further research into teachers' professional development. More detailed classroom studies of assessment practices and their effects on students' learning are needed. By investigating the effect of using some self-assessment techniques on language competence, this study hypothesized that the development of selfassessment can foster language skills. In order to verify this hypothesis different techniques were adapted and injected while teaching "Oral Presentation Skills". It was found that the development of self-assessment helped improve and foster language skills and contributed to the development of reliable monitoring and evaluation, thereby influencing students' progress and attainment. However, an important variable not investigated in this study was the effect of assessment on students' motivation. This might be a focus for a further experimental study and calls for a wider range of assessment strategies.

\section{References}

Allwright, D., \& Bailey, K. (1991). Focus on the language classroom: An introduction to classroom research or language teachers. New York, NY: Cambridge University Press.

Biggs, J. (1999). What the student does: Teaching for enhanced learning. Hager Education Research and Development, 18(1), 57-75.

Carter, R., \& Nunan, D. (2001). The Cambridge guide to teaching English to speakers of other languages. Cambridge, UK: Cambridge University Press.

Chamot, A. U., \& O’Malley, J. M. (1989). The cognitive academic language learning approach: A bridge to the main stream. TESOL Quarterly, 21, 227-249.

Chastain, K. (1988). Developing second language skills. New York, NY: Harcourt Brace Jovanovich.

Davison, C., \& Cummins, J. (2007). Assessment and evaluation in ELT: Shifting paradigms and practices. In International Handbook of English Language Teaching (Vol. 15, pp. 415-420). Boston, MA: Springer Science Business Media, LLC.

Dunn, B., et al. (2004). Genetic footprinting: A functional analysis of the S. cerevisiae genome. Stanford, CA: Stanford University Press.

Genesee, F., Upshur, J. (1996). Classroom-based evaluation in second language education. Cambridge, UK: Cambridge University Press.

Gibbs, G. (2003). Using assessment to support student learning at University of East Anglia. Leeds, UK: Leeds Metropolitan University.

Jabbarifar, T. (2009). The importance of classroom assessment and evaluation in educational system. In Proceedings of the 2nd International Conference of Teaching and Learning (ICTL 2009). INTI University College, Kuching, Malaysia.

Matthes, C., \& Marino, J. (1990). Professional interactions: Oral communication skills in science, technology, and medicine. London, UK: Prentice Hall.

Nunan, D. (1989). Understanding language classrooms. London, UK: Prentice Hall.

O’Malley, J. M., \& Valdez-Pierce, L. (1996). Authentic assessment for English language learners: Practical approaches for teachers. Reading, MA: AddisonWesley.

Rea-Dickins, P. (1994). Evaluation and English language teaching. Language Teaching, 27, 71-91.

Richards, J. C., \& Lockhart, C. (1994). Reflective teaching in second language classrooms. New York, NY: Cambridge University Press.

Sainsbury, E., \& Walker, R. (2007). Assessment as a vehicle for learning: Extending collaboration into testing. Assessment and Evaluation in Higher Education, 33(2), 1-18.

Kuzmenkova, Iu. (2011). Academic project presentations. Moscow, Russia: MSU. 